\title{
Emerging Issues in the Mechanisms of High Pressure Free Radical Ethylene Polymerization: A Review
}

\author{
Ke hinde A. J ${ }^{1}$, Usman M. A ${ }^{1}$, Edoga M. O², Owolabi R. U.,"* \\ ${ }^{1}$ University of Lagos, Chemical Engineering Department, Akoka, Lagos State, Nigeria \\ ${ }^{2}$ Federal University of Technology, Chemical En gineering Department, Minna, Niger State, Nigeria \\ ${ }^{3}$ Fountain University, Industrial and Environmental Chemistry Department P.M.B 4491, Osogbo Osun State, Nigeria
}

\begin{abstract}
The need to improve the performance of the high pressure polymer production process, and timely introduction of new and functionalised products even at reduced production cost which is becoming critical to staying in business has given room for overall studies of the ethylene polymerization process. In this review, emerging issues in the high pressure ethylene polymerization process through free radical approach is unveiled and presented. Different views and approaches of several authors on the tasking issues were compiled, analysed and discussed. Future researchable areas were made clear in this study. Further investigations were also made to model kinetically the high pressure ethylene polymerization reaction in tubular reactors only using mass balances and moment analysis. Although not discussed in this paper, the modeling of heterogeneous polymerization reactions such as precipitation polymerization and emulsion polymerization remains a challenge.
\end{abstract}

Keywords Ethylene Polymerization, Free Radical, Tubular Reactors, Moment Analysis, Precipitation Polymerization, Emulsion Poly merization

\section{Introduction}

The most important industrial reaction of ethylene is its reaction with itself (Poly merization)[1] . Poly merization as defined by Carothers[2] is the intermolecular combinations that are functionally capable of proceeding indefinitely. Polyethylene, the product of the indefinite combination of ethylene monomers at high pressure in the presence of initiators was the unexpected result of an experiment undertaken in the course of a fundamental research in the early 1930 's without a direct commercial target in view. Imperial Chemical Industries (ICI) in England decided to evaluate the effect of ultra-high pressures on some 50 chemical reactions. In 1933, an experiment was carried out, compressing ethylene gas to 1400 bar. A white solid was formed in the heavy steel vessel, which proved to be low-density polyethylene (LDPE). Subsequent work showed that minute traces of oxygen had caused the polymerization[3]. Polyethylene accounted for $30 \%$ of the total annual world poly mer consumption in 2007 (more than 70 million tonnes in 2007)[4] and are the most widely

* Corresponding author:

uthmanrash642@yahoo.com (Owolabi R. U.)

Published online at http://journal.sapub.org/ajps

Copyright (C) 2012 Scientific \& Academic Publishing. All Rights Reserved
70 million tonnes in 2007)[4] and are the most widely utilized synthetic polymers. Tubular process using a very long small diameter tubular reactor and an autoclave process using a well stirred tank reactor are commonly used industrial process for polyethylene synthesis. Hee-Jong Lee et al[5] confirmed that polyethylene products manufactured by these processes differ in their mo lecular architecture and end use properties. Majid[6] reported the scientific, industrial and commercial reasons for the enormous consumption, such as good chemical resistance, zero toxicity, bio-acceptability, good physical and mechanical properties, low cost, ease of fabrication, good raw material availability and low environmental impact[7-11]. From the $\mathrm{S}$ curve of polyethylene technology[12-13], it can be seen that polymerization processes caused revolutionary improvements in polyethylene technology as shown in Figure 1.

In most textbooks and monographs on free radical ethylene polymerization, only very few if any at all commented on the challenges, emerging issues, unsolved problems and future opportunities of this part of macromolecular chemistry (Ethylene polymerization). Therefore, this mini review deals mainly with the identification of cloudy areas and gaps uncovered with a view of creating future researchable areas in free radical ethylene polymerization. 


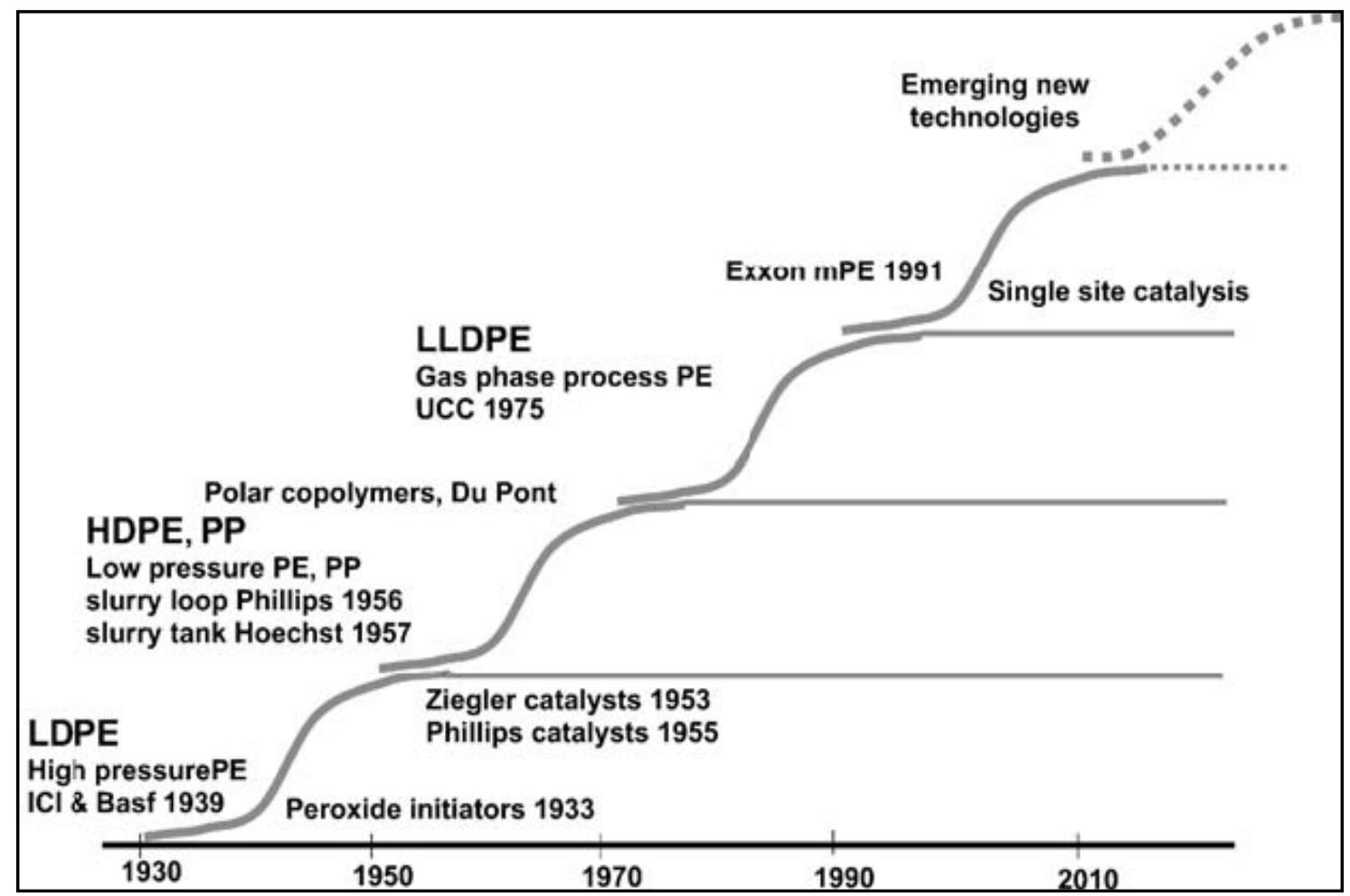

Figure 1. S curve of polyethylene technology [12-13]

\section{Kinetics of Ethylene Polymerization}

The industrial importance of ethylene polymerization has led to extensive studies of its kinetics[14-17]. In this section, a set of reaction mechanisms required to model the kinetics of free radical polymerization of ethylene is described. A unique and unified set of elementary steps for free radical ethylene polymerization is still being debated and yet to be found in open literature. Buback,[18] studied the thermally initiated polymerization of ethylene. His results from the kinetic experiments on pure ethylene carried out at temperatures $180-250{ }^{\circ} \mathrm{C}$ and pressures up to 2500 bars showed that a very slow thermally in itiated reaction resulting in high mo lecular weight polyethylene could be established. The actual mechanism is not known but it can be written as an overall third order reaction. However, many workers in this field[14, 19-22] and recently by Kiparissides[23-24] proposed the kinetic mechanism described as follows;

1. Initiation: (Activation) with Peroxides, Azo Compounds or Oxygen:

\section{$\mathrm{k}_{\mathrm{I}}$}

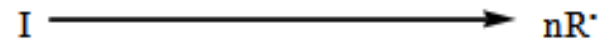

$\mathrm{n}$ is the number of radicals generated which is usually 2 for nonfunctional in itiators.

2. Cha in Initiation:

$$
\mathrm{R}^{*}+\mathrm{M} \longrightarrow \mathrm{k}_{\mathrm{CI}}
$$

3. Thermal In itiation:

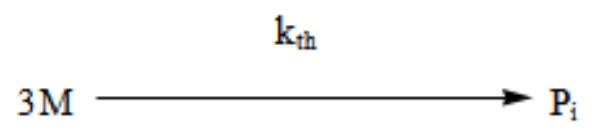

4. Propagation (Growth):

$\mathrm{k}_{\mathrm{p}}$

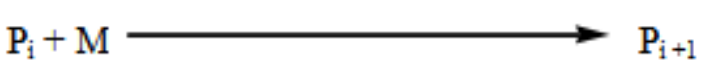

5. Termination by Co mb ination:

$\mathrm{k}_{\mathrm{tc}}$

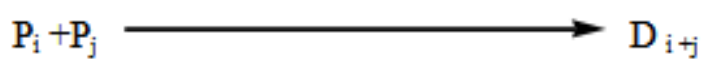

6. Termination by Disproportionation:

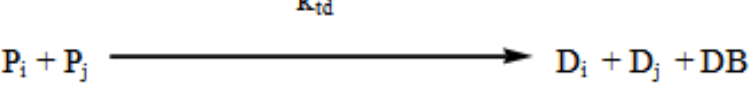

7. Cha in Transfer to Monomer:

$$
\mathrm{k}_{\mathrm{trm}}
$$

$$
\mathrm{P}_{\mathrm{i}}+\mathrm{M} \longrightarrow \mathrm{P}_{1}+\mathrm{Di}
$$

8. Chain Transfer to Polymer (Intermolecular transfer/LCB):

$$
\mathrm{P}_{\mathrm{i}}+\mathrm{D}_{\mathrm{j}} \longrightarrow \mathrm{Jxk}_{\mathrm{trp}}
$$

9. Cha in Transfer to Solvent/Modifier/Agent:

$$
\mathrm{k}_{\mathrm{trs}}
$$$$
\mathrm{P}_{\mathrm{i}}+\mathrm{S} \longrightarrow \mathrm{D}_{\mathrm{i}}+\mathrm{P}_{1}
$$

10. Backb iting (Intermolecular transfer/SCB): 


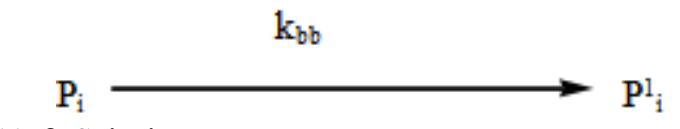

11. $\beta$-Scis sion:

$$
\mathrm{k}_{\beta}
$$

$\mathrm{P}_{\mathrm{i}}$ $\mathrm{D}_{\mathrm{i}-\mathrm{k}}+\mathrm{P}_{\mathrm{k}}+\mathrm{DB}$

Tsutomu and Masatsugu[26] in their comprehensive review on the kinetics of polymerizations of various types classified poly merization according to:

- the type of initiators,

- kind of monomer,

- mode of the addition of monomer to the propagating species,

- or electronic structures of the propagating species.

He further argued that the qualitative nature of elementary reactions of polymerization in the frame of these classifications can be conveniently expressed. Polyethylene has been manufactured by the high pressure process for over 50 years but profound comprehension of the reaction mechanis ms and kinetic analysis of the process has posed a challenge in developing a cohesive understanding of the process as witnessed by the survey of the literature $[27-35,21]$.

\section{Chemistry and Effectiveness of Initiators}

According to Zabisky[36], Oxygen initiation of ethylene polymerization was first reported by Fawcett et al and has been used commercially in both tubular and batch reactors. It is well known that oxygen serves as an inhibitor in free radical polymerization at lower temperatures. Oxygen may react with rad icals or mono mers to form poly meric pero xides. These peroxides may then decompose to initiate the polymerization. Several authors including Thies and Schoenemann[37] have tried to model oxygen in itiation by assuming an overall second order reaction of the type neglecting the inhibition reactions but with moderate success.

$$
\mathrm{O}_{2}+\mathrm{M} \quad \underset{\mathrm{kdO2}}{\longrightarrow} 2 \mathrm{R} \text {. }
$$

This initiation method is very convenient due to availability of oxygen, its cost and simplicity of its supply into the reaction system without additional components and special installations. However, oxygen initiation is also known to have some significant drawbacks. Kondratiev and Ivanchev[38] reported that oxygen initiation is only possible at temperatures above $170^{\circ} \mathrm{C}$ and pressures above 860 bars. However, the application of low temperature peroxides in oxygen initiated processes affords the advantage of additional polymer yield at the low temperature initiation step (increase of conversion by $1 \%$ ). Dhib and Nidawy[39] stated in their report that the chemistry and thermal behaviour of organic peroxides used as initiators in free radical polymerization have been the focus of many researchers who are investigating potential routes to improve the efficiency of polymerization reactions. Under thermal effects, organic peroxides exhibit different rates of decomposition owing to their dissimilar half-life temperatures. Focusing on the chemistry and kinetics of certain organic peroxides, Luft and Seidl[40] carried out a series of sound detailed studies on their kinetic decompositi on, reaction rates, effectiveness and effects on polyethylene product $[41-43,40,44]$. The studies incorporated the setting-up of a database of the most common peroxide initiators in the production of polyethylene. Over 20 initiators have been used in experiments to produce LDPE polymers and the consumed amount of each initiator constituted the basic criterion of assessing the initiator effectiveness. Continuing a previous experimental work Luft and Seid1,[40], Luft and Dorn[44] as reported by Dhib and Nidawy[39] studied the effectiveness of four difunctional in it iato rs: 2,5-dimethylhe xane-2-t-butylpero xy-5-perpivalat e, 2,5-d imethylhe xane-2,5-b is-perpiva late, 2, 2-bis (tert-utylp ero xy ) butane and 2,5-dimethylhe xane-2,5-di-t-butyl-pero xi de, that were judged suitable for high-pressure polymerization of ethylene at optimum temperatures of 273 , 235, 268 and $287^{\circ} \mathrm{C}$, respectively where difunctional initiators were observed to accelerate the polymerization rate and produce polymers of higher molecular weight at high temperature compared to monofunctional in itiators. Besides, the difunctional in itiator can produce special polymers like star and hyperbranched polymers. Puts and Sogah[45] and Hawker et al[46] in their report explained that the use of a dual initiator (also named bifunctional in itiator, asymmetric difunctional in itiator or "double-headed" init iator), or mo re generally a heterofunctional initiator, shows many advantages compared to the classical methods for the synthesis of block copolymers by combination of mechanistically incompatible monomers ( Fig.2). Heterofunctional initiators contain two or more different initiation sites that are capable of initiating concurrent polymerization mechanis ms independently and selectively. This approach provides the opportunity to combine mechanistically incompatible monomers into one macromolecule without the need for intermediate transformation and protection steps, which can offer new opportunities in the design and application of functional organic materials. In contrast to mechanism transformation, where a transformation of the propagating chain end takes place, heterofunctional initiators can initiate several polymerization mechanis ms, yielding block copolymers in a direct way. A requirement for such a mechanism is that each initiating group is stable in the different polymerization circumstances of the other type of polymerization.

Though multifunctional initiators are believed to provide two advantages over traditional monofunctional initiators, with a higher number of functional sites per molecule, they are able to increase polymer production while simultaneously maintaining or increasing polymer molecular weight. Examination of the literature indicates the majority of academic and industry published studies have investigated difunctional initiators with most focusing on styrene. Matthew[48] in his $\mathrm{Ph} . \mathrm{D}$ thesis reported that 
tetrafunctional initiator, JWEB 50, was systematically investigated for a variety of monomer systems in order to develop a better understanding of the behaviour of multifunctional initiators in free radical polymerizations. But, in all the kinetic decomposition of multi/difunctional peroxides is still a controversial is sue according to Dhib and Nidawy[39].

\section{Kinetic Parameters and Estimation}

For each of the elementary steps stated in equation (1) to (11), three parameters were used to determine the value of their kinetic rate constant at any temperature and pressure according to the modified Arrhenius equation:

$$
\mathrm{k}=\mathrm{ko} \exp \left[-\left(\mathrm{E}_{\mathrm{a}}+\mathrm{V}_{\mathrm{a}} \mathrm{P}\right) / \mathrm{RT}\right]
$$

Where $\mathrm{k}_{\mathrm{o}}=$ frequency factor $(1 / \mathrm{mol} . \mathrm{s})$

$\mathrm{E}_{\mathrm{a}}=$ activation energy (cal/ $\left.\mathrm{mol}\right)$

$\mathrm{V}_{\mathrm{a}}=$ activation volume (cal/atm.mol)

$\mathrm{P}=$ pressure $(\mathrm{atm})$

$\mathrm{T}=$ temperature $(\mathrm{K})$

Examination of compilations of literature values of rate parameters often reveals a very wide range of reported values for any particular rate parameter in spite of the great number of papers published on the modeling of LDPE reactors. Gupta et al [32], Ehrlich and Mortimer[14], Goto et al[21], Lee and Marano[30], Takahashl and Ehrlich[33], Thies and Schoenemann,[37]. Kiparissides et al [49] in their review attributed the inconsistency of published set of rate constants to the complexity of the reaction, the large number of kinetic parameters to be determined experimentally and the wide range of experimental conditions over which the kinetic parameters were estimated. With such a wide range of values, it is often possible that conflicting mechanistic suppositions can be supported with 'evidence' from the literature. To overcome the wide divergence in literature values of kinetic parameters for free radical poly merizations under ostensibly the same conditions, agreed values are given to some fundamental kinetic parameters for simple monomers. If we just consider the rate of polymerization, the ratio $\mathrm{k}_{\mathrm{p}} / \mathrm{k}_{\mathrm{t}}^{0.5}$ is important. Fig. 3. shows this ratio as reported by several authors. As discussed recently in[50], evidence of significant variation of kinetic parameters was further revealed as contained in Table 1.0 where, some of the rate constants of propagation, termination and transfer to mono mer are tabulated with other values from literature.

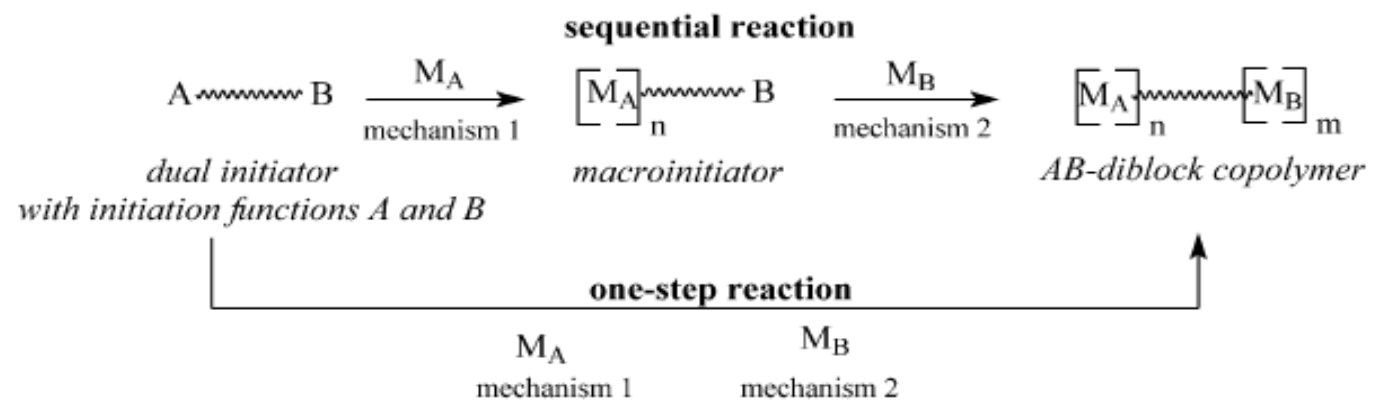

Figure 2. Schematic representation of the principle of heterofunctional initiators, more specifically dual initiators.[47]

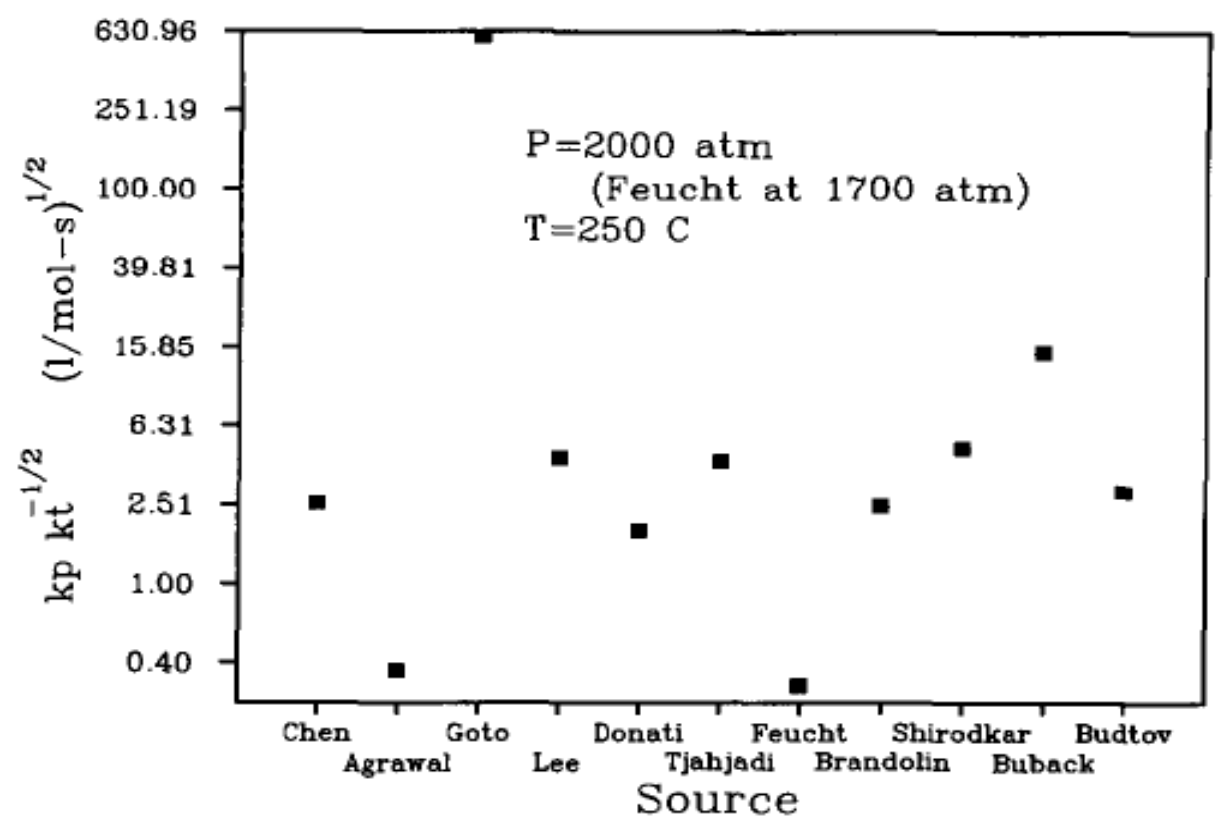

Figure 3. A sampling of the rate parameters for ethylene polymerization from various sources. 36] 
Table 1. Reaction Rate Constants In EthylenePolymerization[39]

\begin{tabular}{|c|c|c|c|c|c|c|}
\hline \multirow{3}{*}{$\begin{array}{c}\text { Rate } \\
\text { Constant }\end{array}$} & \multirow[b]{3}{*}{$\mathrm{A}(1 / \mathrm{s})$} & \multirow[b]{3}{*}{$\mathrm{E}(\mathrm{cal} / \mathrm{mol})$} & \multirow{3}{*}{$\begin{array}{l}{[21]} \\
\mathrm{k}=\mathrm{A} \exp \left(-\mathrm{E} / \mathrm{R}_{1} \mathrm{~T}-\Delta \mathrm{vP} / \mathrm{R}_{2} \mathrm{~T}\right) \\
\quad \Delta \mathrm{v}(\mathrm{cm} 3 / \mathrm{mol})\end{array}$} & \multirow{2}{*}{\multicolumn{3}{|c|}{$\begin{array}{l}{[53]} \\
k=A \exp \left(-E / R_{1} T-\Delta v P / R_{2} T\right)\end{array}$}} \\
\hline & & & & & & \\
\hline & & & & $\mathrm{A}(1 / \mathrm{s})$ & $\mathrm{E}(\mathrm{cal} / \mathrm{mol})$ & $\Delta \mathrm{v}(\mathrm{cm} 3 / \mathrm{mol})$ \\
\hline $\mathrm{k}_{\mathrm{th}}$ & --- & --- & --- & $5.97 \mathrm{e} 7$ & $68,080.00$ & 0.00 \\
\hline $\mathrm{k}_{\mathrm{p}}$ & $5.63 \mathrm{e} 11$ & $10,520.00$ & -17.91 & $4.01 \mathrm{e} 5$ & 4210.00 & -16.80 \\
\hline $\mathrm{k}_{\mathrm{tc}}$ & $3.00 \mathrm{e} 11$ & 3000.00 & 12.61 & $8.71 \mathrm{e} 8$ & 3652.62 & 9.21 \\
\hline $\mathrm{k}_{\mathrm{trm}}$ & --- & --- & --- & $1.20 \mathrm{e} 5$ & $14,400.00$ & 0.00 \\
\hline $\mathrm{k}_{\beta}$ & $5.82 \mathrm{e} 11$ & $15,760.00$ & 21.86 & $4.40 \mathrm{e} 9$ & $19,100.00$ & -9.90 \\
\hline $\mathrm{k}_{\mathrm{fps}}$ & $1.75 \mathrm{e} 12$ & $14,080.00$ & -4.26 & $7.60 \mathrm{e} 9$ & $19,100.00$ & -10.00 \\
\hline $\mathrm{k}_{\mathrm{b}}$ & $5.85 \mathrm{e} 11$ & $13,030.00$ & 22.73 & $1.20 \mathrm{e} 10$ & $14,800.00$ & 0.00 \\
\hline
\end{tabular}

$\mathrm{R}_{1}=1.98 \mathrm{cal} / \mathrm{mol} . \mathrm{k}, \mathrm{R}_{2}=82 \mathrm{~cm} 3 \mathrm{~atm} / \mathrm{mol} . \mathrm{k}$

Table 2. Literature Comparison of Reaction Condition, Molecular weight and Polydispersity[51]

\begin{tabular}{|c|c|c|c|c|c|}
\hline Sources & $\mathbf{T},{ }^{\mathbf{0}} \mathbf{C}$ & $\mathbf{X} \%$ & $\mathbf{M}_{\mathbf{n}}$ & $\mathbf{M}_{\mathbf{w}}$ & PDI \\
\hline$[51]$ & $140-231$ & $10.6-14.2$ & $32,000-54,000$ & $82,300-112,100$ & $2.0-2.78$ \\
\hline$[52]$ & $227-357$ & $\approx 10.05$ & & $40,000-87,000$ & $1.92-2.35$ \\
\hline$[53]$ & & $24.3-29.0$ & $15,900-26,400$ & $108,000-220,000$ & $6.79-8.30$ \\
\hline$[36]$ & & $16.3-22.9$ & $15,900-32,700$ & $38,000-115,000$ & $2.3-3.5$ \\
\hline$[49]$ & & $\approx 16$ & 19,964 & 133,644 & 6.69 \\
\hline$[32]$ & $110-285$ & $\approx 28$ & $500-110,000$ & & $2.0-4.6$ \\
\hline$[54]$ & $70-206$ & $6.4-14.3$ & $39,882-39,986$ & & $3.0-7.0$ \\
\hline
\end{tabular}

\section{Ethylene Conversion/Polymer Molecular Weight}

Literature search shows that common ethylene conversion obtained by various researchers falls within the range of $14-$ $24 \%$ as shown in Table 2.

Dhib and Nidawy,[39] however observed that the thermodynamic conditions of the process hinder ethylene from going to full conversion. Other than recycling the product, one way of improving the mono mer conversion is to initiate the polymerization with difunctional organic peroxides. Due to the dual functionality of difunctional peroxide, the ethylene conversion they obtained from their model was about twice as much as that obtained with monofunctional peroxide, for only a half amount of the initial initiator concentration. However, the setback of obtaining only limited low conversion of ethylene in high-pressure polymerization has been persistently an unpleasant and discouraging reality in spite of the classical approach to enhancing the conversion upon recycling the product. Another route of imp roving ethylene conversion in this kind of polymerization process is to investigate the effectiveness of initiators.

Aside the conversion, the production of polymers with desired end-use properties is of significant financial importance to the polymer industry. One of the most important molecular properties that control the end-use characteristics of polymers is the molecular weight distribution (MWD) as it directly affects the physical, mechanical and rheological properties of the final product[55]. The molecular weight distribution of a polymer can be characterized by the number average molecular weight (Mn), weight average molecular weight (Mw), and polydispersity (PD). MWD/PDI is considered as a fundamental property that determines polymer properties and thus its applications. An ideal polymer contains only one

type of polymer with the same architecture, microstructure and chain length as shown for the polymer chain composition I in Scheme 1[56].
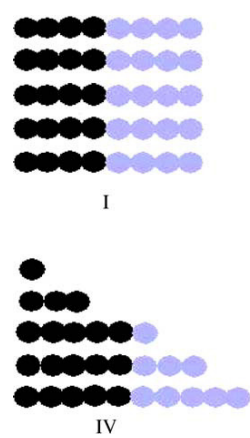

Figure 4. Scheme 1. Different Polymer Chain Compositions

Such a polymer chain composition has a molecular weight distribution of 1.00 , as the molecular weight distribution (MWD) is a quotient of the weight average molecular weight $M \mathrm{w}$ and the number average molecular weight $\mathrm{Mn}$. In general, the MWD gives a value of the uniformity of the polymer sample. The higher the MWD value, the poorer is the uniformity of the polymer's chain composition. Principally, polymeric chain compositions can be divided into the five different types shown in Scheme 1 (Fig.4.)

\section{Harsh Operating Conditions}

Large number of the now available poly mers are obtained, on industrial scale, through high pressure process and any improvement of the industrial process has important economic consequences. In both tubular and autoclave reactors, a free radical mechanism using initiators such as peroxides or oxygen takes place at pressures ranging from 1,000 to 3000 atm[49]. Free radical polymerization of ethylene is carried out at high pressure and elevated 
temperature[57]. Temperatures exceeding $300{ }^{\circ} \mathrm{C}$ cause ethylene to decompose and are not recommended in practice. The high-pressure process is usually a bulk polymerization initiated by organic peroxide. The high pressures $(>2000$ bars $)$ and temperatures $\left(>250^{\circ} \mathrm{C}\right)$ make it difficult to obtain accurate kinetic constants using small scale laboratory experiments. Thus, one has to rely on published literature for kinetic data. Unfortunately, there is very little agreement between the various publications.

Over the last few decades, a lengthy list of academicians and industrialists incessantly attempted to establish a unifed tangible understanding of ethylene polymerisation in high-pressure autoclave reactors[21, 58-60] and tubular reactors [28, 61] mainly because the technical properties of polymer products are mainly determined by the conditions of the polymerization reaction. Kiparissides et al.[49] reported that low pressure ionic ethylene polymerization processes have been developed for the production of high density polyethylene and medium density polyethylene.The process requires low pressure(8-80 atm) and temperatures less than $150{ }^{\circ} \mathrm{C}$ using a transition metal catalyst of the Ziegler-Natta or Phillip type. Though the process has gained a lot of popularity in the polyolefin industry still, there is the need for a strong reconsideration of polymerization processes of the most common monomers such as ethylene with emphas is on new initiating systems under low pressure and "uncatalyzed" polymerizations. Similarly, despite the commercial success of gas phase ethylene polymerization technology, the public literature contains no accounts of fundamental scale-up studies of gas phase processes. There is further need, therefore, for a co mprehensive understanding of detailed polymerization behavior in gas phase polymerization. A challenge for academic researchers studying gas phase polymerization of ethylene is how to scale down commercial processes for experimental laboratory studies.

\section{Ethylene Polymerization Kinetic Model Development for a Tubular Reactor}

According to Xie et al.[62] reactor modeling is the determination of a quantitative relationship between reactor performance and reactor operating conditions. It requires comprehensive understanding of polymerization processes, physical phenomena, and chemical reaction mechanisms. The importance and benefits of reactor modeling have been widely recognized by both industrial and academic researchers. The application capability of a model depends on scope of the modeling effort. Ray[63-64] defined a modeling hierarchy as microscale, mesoscale, and macroscale, according to the characteristics of the polymerization reactor systems. The relationships between modeling scale and polymerization systems are similarly outlined in Figure 5 after Ray[63-64]. The emphas is of each modeling level, in particular for ethylene polymerization systems, can be summarized as follows:
1. Microscale modeling: Polymerization rate development, or poly mer yield; reactant species distribution; molecular weight development and its distribution; chemical composition of polymer chains and its distribution; microstructures of polymer chains, including chain branching, unsaturated groups, and sequence distribution.

2. Mes os cale modeling: Interphase heat and mass transfer; intraphase heat and mass transfer; fluid mechanics and micro-mixing; polymer particle morphology development; polymer particle size and distribution.

3. Macroscale modeling: macro-mixing and residence time distribution; overall material and energy balance; heat and mass transfer from the reactor; reactor dynamics and control; polymer grade transition and control.

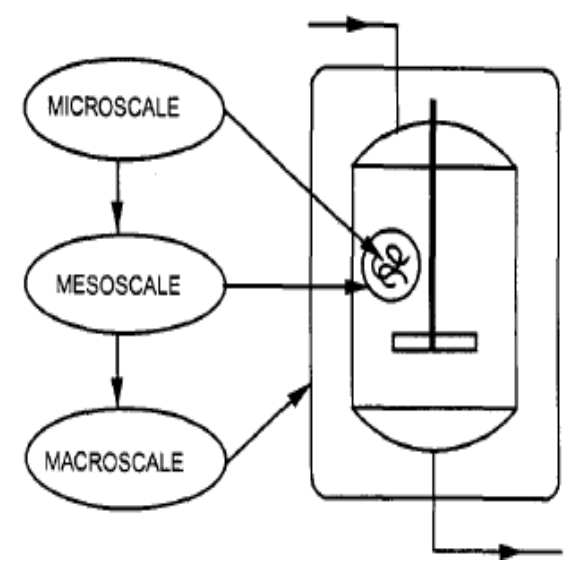

Figure 5. Levels of polymerization reactor modelling[63-64]

There are no definitive boundaries between these modeling levels. In fact, they often overlap during modeling studies. For instance, knowledge of some microscale modeling is required for mesoscale modeling studies, and macroscale modeling depends upon understanding of microscale and mesoscale phenomena. A complete model for ethylene polymerization, including all three levels, has not been developed in the literature. However, significant modeling efforts with emphasis on specific levels have been published. Microscale and mesoscale modeling studies are normally reported as kinetic modeling in the literature. Macroscale modeling is often referred to as dynamic modeling.

Therefore, search for more realistic kinetic schemes, able to describe to a greater extent the processes and having general applicability to different monomers, homopolymerization and co-polymerization to complete conversion should be an area of focus by researchers.To describe the conservation of various molecular species present in a reactor, there is the need to know their corresponding net production rates. The expressions for these rate functions can be obtained by combining the various elementary reactions describing the generation of and the consumption of initiator(s), monomers, solvents, dead and live macromolecules.

The application of mass balances to the Equation (1) to (11) leads to the following: 


$$
\begin{gathered}
\mathrm{r}_{\mathrm{R}}=2 f k_{I} C_{I}-k_{C I} C_{M} C_{R} \\
\mathrm{r}_{\mathrm{M}=}-\left[k_{C I} C_{M} C_{R}+k_{t h} C^{3} M+k_{p} \sum_{i=1}^{\infty} C_{p i} C_{M}+k_{t r m} \sum_{i=1}^{\infty} C_{p i} C_{M}\right] \\
\mathrm{r}_{\mathrm{pi}}=k_{C I} C_{M} C_{R}+k p \sum_{i=1}^{\infty} C_{p i} C_{M}-k p \sum_{i=1}^{\infty} C_{p i} C_{M}-k_{t r m} \sum_{i=1}^{\infty} C_{p i} C_{M}+k_{t r p} \sum_{j=1}^{\infty} C_{p j} \sum_{i}^{\infty} i . C_{D i}-k t r p \sum_{i=1}^{\infty} C_{p i} \sum_{j=1}^{\infty} j . C_{D j} \\
-k_{t r s} C_{S} \sum_{i=1}^{\infty} C_{p i}-k_{t c} \sum_{i=1}^{\infty} C_{p i} \sum_{j=1}^{\infty} C_{p j}-k_{t d} \sum_{i=1}^{\infty} C_{p i} \sum_{j=1}^{\infty} C_{p j}-k_{b b} \sum_{i=1}^{\infty} C_{p i} \text { (Live chains) } \\
k_{t r m} \sum_{i=1}^{\infty} C_{p i} C_{M}+k_{t r p} \sum_{i=1}^{\infty} C_{p i} \sum_{j}^{\infty} j \cdot C_{D j}-k_{t r p} \sum_{j=1}^{\infty} C_{p j} \sum_{i=1}^{\infty} i \cdot C_{D i}+k_{t r s} C_{S} \sum_{i=1}^{\infty} C_{p i}+0.5 k_{t c} \sum_{j=1}^{\infty} C_{p j} \sum_{j=1}^{\infty} C_{P j} \\
+k_{t d} \sum_{i=1}^{\infty} C_{p i} \sum_{j=1}^{\infty} C_{p j}
\end{gathered}
$$

By introducing the zeroth, first and second moments, the kinetic mechanisms can be represented with a finite number of model equations and the mathematical models are capable of predicting the number and weight average mo lecular weights and the polydispersity of the polymer produced;

The leading mo ments of the total number chain length distributions (TNCLDs) of live and dead poly mer chains are defined by Arriola[65] as:

$$
\begin{aligned}
\text { Live } \lambda_{\mathrm{k}} & =\sum_{i=1}^{\infty} i^{k}\left[P_{i}\right] \mathrm{k}=0,1,2 \\
\text { Dead } \mu_{\mathrm{k}} & =\sum_{j=1}^{\infty} j^{k}[D j] \mathrm{k}=0,1,2
\end{aligned}
$$

Following the approach of Zabisky et al.[36] and Metzler et al.[66], the first three mo ments of polymer radicals were used to calculate the number and average molecular weights. The Number- and weight- average molecular weights are defined respectively as:

$$
\begin{aligned}
M_{N} & =M_{W 0} \frac{\lambda_{1}+\mu_{1}}{\lambda_{0}+\mu_{0}} \\
M_{W} & =M_{W 0} \frac{\lambda_{2}+\mu_{2}}{\lambda_{1}+\mu_{1}} \\
P D & =\frac{M_{W}}{M_{N}}
\end{aligned}
$$

Where $M_{W 0}$ is the monomer molecular weight.

Therefore,

$$
\begin{aligned}
& \frac{d \lambda_{k}}{d t}=r_{\lambda k}=\sum_{i=1}^{\infty} \frac{d p_{i}}{d t}=\sum_{i=1}^{\infty} i^{k} r_{p i} \\
& \frac{d \mu_{k}}{d t}=r_{\mu k}=\sum_{j=1}^{\infty} \frac{d D_{j}}{d t}=\sum_{i=1}^{\infty} j^{k} r_{D j}
\end{aligned}
$$

Live Polymer Chains Moments

Multiplying Equation (17) by $i^{k}$

$$
\begin{array}{r}
\mathrm{r}_{\mathrm{k}}=\left[\mathrm{k}_{\mathrm{CI}} \mathrm{C}_{\mathrm{M}} \mathrm{C}_{\mathrm{R}}-\mathrm{k}_{\mathrm{p}} \sum \mathrm{C}_{\mathrm{Pi}-1} \mathrm{C}_{\mathrm{M}}-\mathrm{k}_{\mathrm{p}} \sum \mathrm{C}_{\mathrm{Pi}} \mathrm{C}_{\mathrm{M}}-\mathrm{k}_{\mathrm{trm}} \sum \mathrm{C}_{\mathrm{Pi}} \mathrm{C}_{\mathrm{M}}+-\mathrm{k}_{\mathrm{trp}} \sum \mathrm{C}_{\mathrm{Pj}} \sum \mathrm{i} \cdot \mathrm{C}_{\mathrm{Di}}\right. \\
\left.-\mathrm{k}_{\mathrm{trp}} \mathrm{C}_{\mathrm{Pi}} \mathrm{j} \cdot \mathrm{C}_{\mathrm{Dj}}-\mathrm{k}_{\mathrm{trs}} \mathrm{C}_{\mathrm{S}} \sum \mathrm{C}_{\mathrm{Pi}}-\mathrm{k}_{\mathrm{tc}} \sum \mathrm{C}_{\mathrm{Pi}} \sum \mathrm{C}_{\mathrm{Pj}}-\mathrm{k}_{\mathrm{td}} \sum \mathrm{C}_{\mathrm{Pi}} \sum \mathrm{C}_{\mathrm{Pj}}-\mathrm{k}_{\mathrm{bb}} \sum \mathrm{C}_{\mathrm{Pi}}\right] \mathrm{i}^{\mathrm{k}}
\end{array}
$$

Dead Poly mer Chains Moments

Multiplying Equation (18) by $\mathrm{j}^{\mathrm{k}}$ 


$$
\mathrm{r}_{\mu_{\mathrm{k}}}=\left[\mathrm{k}_{\mathrm{trm}} \sum \mathrm{C}_{\mathrm{Pi}} \mathrm{C}_{\mathrm{M}}+\mathrm{k}_{\mathrm{trp}} \sum \mathrm{C}_{\mathrm{Pi}} \sum \mathrm{j} \cdot \mathrm{C}_{\mathrm{Dj}}-\mathrm{k}_{\mathrm{trp}} \sum \mathrm{C}_{\mathrm{Pj}} \sum \mathrm{i} \cdot \mathrm{C}_{\mathrm{Di}}+\mathrm{k}_{\mathrm{trs}} \mathrm{C}_{\mathrm{S}} \sum \mathrm{C}_{\mathrm{Pi}}+0.5 \mathrm{k}_{\mathrm{tc}} \sum \mathrm{C}_{\mathrm{Pj}} \sum \mathrm{C}_{\mathrm{Pi} \mathrm{j}}+\mathrm{k}_{\mathrm{td}} \sum \mathrm{C}_{\mathrm{Pi}} \sum \mathrm{C}_{\mathrm{Pj}}\right] \mathrm{j}
$$

The other reaction rates of interest can be expressed in terms of moment equations as:

$$
\begin{aligned}
& \text { Initiator consumption rate: } r_{I}=-k_{I} C_{I} \\
& \text { Primary Radical rate: } \mathrm{r}_{R}=2 \mathrm{fk}_{\mathrm{I}} \mathrm{C}_{\mathrm{I}}-\mathrm{k}_{\mathrm{CI}} \mathrm{C}_{\mathrm{M}} \mathrm{C}_{\mathrm{R}} \\
& \text { Monomer Consumption rate: } \left.\mathrm{r}_{\mathrm{M}}=-{ }_{-} \mathrm{k}_{\mathrm{CI}} \mathrm{C}_{\mathrm{M}} \mathrm{C}_{\mathrm{R}}+\mathrm{k}_{\mathrm{p}} \lambda_{0} \mathrm{C}_{\mathrm{M}}+\mathrm{k}_{\mathrm{rrm}} \lambda_{0} \mathrm{C}_{\mathrm{M}}\right] \\
& \text { Solvent }(\mathrm{CTA}) \text { rate: } \mathrm{r}_{\mathrm{S}}=-\mathrm{k}_{\mathrm{trS}} \mathrm{C}_{\mathrm{S}} \lambda_{0} \\
& \text { LCB reaction rate: } r_{\mathrm{LCB}}=\mathrm{k}_{\mathrm{trp}} \lambda_{0} \mu_{1} \\
& \text { SCB reaction rate: } \mathrm{r}_{\mathrm{SCB}}=\mathrm{k}_{\mathrm{bb}} \lambda_{0}
\end{aligned}
$$

Usually, one needs to know the leading mo ments (i.e., $\lambda_{0}, \lambda_{1}, \lambda_{2}$ and $\mu_{0}, \mu_{1}, \mu_{2}$ of the "live" and "dead" poly mer distributions) to calculate the values of the number-average molecular weight $(\mathrm{Mn})$, and number- average molecular weights(Mw).

$$
\begin{gathered}
r \lambda_{k}=\frac{d \lambda_{k}}{d t}=\frac{d \lambda_{k}}{d z} \cdot v \\
\text { where } v=\frac{d z}{d t}
\end{gathered}
$$

Following the approach of Zabisky et al.[36], as reported by Fred et al.[51], the concentration of live polymer concentration is considered to be constant so that

Considering Eq. (26), putting $\mathrm{k}=0$

$$
\frac{d \lambda_{k} v}{d z}=0
$$

$$
\begin{gathered}
\lambda_{0}^{2} k_{t}+\lambda_{0}\left[k_{t r m} C_{m}+k_{t r s} C_{S}+k_{b b}\right]-k_{c i} C_{m} C_{R}=0 \\
\lambda_{0}=\frac{-k_{l} \pm \sqrt{k_{l}^{2}-8 f k_{t} k_{i} C_{I}}}{2 K_{t}} \\
k_{c i} C_{m} C_{R}-\lambda_{1}\left\{k_{t r m} C_{m}+k_{t r p} \mu_{1}+k_{t r s} C_{S}+\lambda_{0}\left[K_{t c}+k_{t d}\right]+k_{b b}\right\}+k_{t r p} \lambda_{0} \mu_{2}=0 \\
\lambda_{1}=\frac{2 f k_{i} C_{i}+k_{t r p} \lambda_{0} \mu_{2}}{\left\{k_{t r m} C_{m}+k_{t r p} \mu_{1}+k_{t r s} C_{S}+\lambda_{0} k_{T}+k_{b b}\right.} \\
\lambda_{2}\left\{k_{t r m} C_{m}+k_{t r p} \mu_{1}+k_{t r s} C_{S}+\lambda_{0}\left[K_{t c}+k_{t d}\right]+k_{b b}\right\}=k_{c i} C_{m} C_{R}+k_{t r p} \lambda_{0} \mu_{3} \\
\lambda_{2}=\frac{2 f k_{i} C_{i}+k_{t r p} \lambda_{0} \mu_{3}}{\left\{k_{t r m} C_{m}+k_{t r p} \mu_{1}+k_{t r s} C_{S}+\lambda_{0} k_{T}+k_{b b}\right.} \\
\mathrm{r} \mu_{0}=\frac{d \mu_{0}}{d t}=k_{t r m} \lambda_{0} C_{m}+k_{t r s} C_{S} \lambda_{0}+\lambda_{0}^{2}\left[0.5 K_{t c}+k_{t d}\right] \\
\mathrm{r} \mu_{1}=\frac{d \mu_{1}}{d t}=k_{t r m} \lambda_{1} C_{m}+k_{t r p} \lambda_{0} \mu_{2}-k_{t r p} \lambda_{1} \mu_{1}+k_{t r s} C_{S} \lambda_{1}+\lambda_{1} \lambda_{0}\left[0.5 K_{t c}+k_{t d}\right] \\
\mathrm{r} \mu_{2}=\frac{d \mu_{2}}{d t}=k_{t r m} \lambda_{2} C_{m}+k_{t r p} \lambda_{0} \mu_{3}-k_{t r p} \lambda_{2} \mu_{1}+k_{t r s} C_{S} \lambda_{2}+\lambda_{2} \lambda_{0}\left[0.5 K_{t c}+k_{t d}\right]
\end{gathered}
$$

There is a higher moment, $\mu_{3}$ which would require an additional differential equation. Following the approach of several authors [36,39], the closure of Hulburt and Katz[67] gives the following expression for

$$
\mu_{3}=\frac{\mu_{2}}{\mu_{0} \mu_{1}}\left[2 \mu_{0} \mu_{2}-\mu_{1}^{2}\right]
$$

Zabisky et al[36] as reported by Fred et al.[51] have satisfactorily tested this method by comparing simulation results with the data from a commercial plant.

\section{Conclusions}

In this review, some issues concerning the mechanism of ethylene polymerization, chemistry and effectiveness of initiators, ethylene conversion/polymer molecular weight, harsh operating conditions, model parameters estimation techniques, were discussed. The areas that need further research attention have been identified. One of the outstanding issues is to develop more efficient parameter estimation techniques to strictly limit the wide discrepancies in published data on ethylene polymerization kinetic parameters and the possibility of synthesizing polyethylene of improved quality under mild conditions. Kinetic modeling plays an important role in the design of polymerization

reaction conditions with which to tailor a polymer's mo lecular arch itecture. This area was not left out as attempt was also made to develop appropriate kinetic model for ethylene polymerization in a tubular reactor based on experimentally determined elementary steps found in the literature which could be used in estimating the first three moments of both the live and the dead radicals which are used to estimate number average molecular weight, weight average molecular weight and polymer polydispersity.

\section{SYMBOLS USED}

$\mathrm{C}_{\mathrm{I}}$ Concentration of initiation, $\mathrm{mol} / \mathrm{L}$

$\mathrm{C}_{\mathrm{M}}$ Concentration of monomer $\mathrm{mo} / / \mathrm{L}$

$C_{R}$ Concentration of free radical $1 / \mathrm{S}$

$\mathrm{C}_{\mathrm{S}}$ Concentration of solvent $\mathrm{mol} / \mathrm{L}$

$D_{i}$ ead poly mer or dead chains

f Efficiency of orig inal initiation

I Initiation

$\mathrm{k}_{\mathrm{bb}}$ Rate constant of backbiting $1 / \mathrm{S}$

$\mathrm{k}_{\mathrm{I}}$ Rate constant of oxygen/peroxide initiation, 1/S

$\mathrm{k}_{\mathrm{P}}$ Rate constant of propagation, $1 / \mathrm{mol}$.S

$\mathrm{k}_{\mathrm{tc}}$ Rate constant of termination by combination, $1 / \mathrm{mol}$.S

$\mathrm{k}_{\text {th }}$ Rate constant of monomer thermal in itiation, $1 / \mathrm{S}$ 
$\mathrm{k}_{\mathrm{trm}}$ Rate constant of chain trans fer to monomer, 1/mol.L

$\mathrm{k}_{\text {trp }}$ Rate constant of chain trans fer to polymer, $1 / \mathrm{mol}$.S

$\mathrm{k}_{\text {trs }}$ Rate constant of chain trans fer to solvent, $1 / \mathrm{S}$

$\mathrm{k}_{\beta}$ Rate constant of $\beta$-scission to secondary radical. $1 / \mathrm{S}$

LCB Long chain branching

M Monomer

$\mathrm{M}_{\mathrm{wo}}$ Monomer molecular weight

$\mathrm{P}_{\mathrm{i}}$ Live radical, radical polymer, live polymer or live chains

PDI Polydispersity Index

$\mathrm{R}$ Initiator radical

S Solvent

SCB Short chain branching

$\lambda$ Live polymer moment

$\mu$ Dead polymer moment

$\lambda_{0}$ Zeroth live poly mer mo ment

$\lambda_{1}$ First live poly mer mo ment

$\lambda_{2}$ Second live poly mer mo ment

$\mu_{0} \quad$ Zeroth dead polymer mo ment

$\mu_{1} \quad$ First dead polymer moment

$\mu_{2}$ Second dead polymer moment

$\mathrm{i}, \mathrm{j}$ Ultimate monomer unit in the radical chain

\section{REFERENCES}

[1] Mc Duell, G.R., (1984), A-level chemistry,Charlse Letts Ltd.

[2] Carothers, W.H. (1931), Polymerization, tiber die angeblichen Isomerien bei cyclischen $\mathrm{O}$ xalsaur eester, Chem. Rev., 8, 353-426.

[3] Charlie, E.S. (2006), Exxon Mobil High Pressure Process Technology for LDPE.

[4] Scheidl, K. (2008), Polyethylene-Polypropylene Chain Global PE/PP Industry Report. Maack Business Services, MaacK/Scheidl Partnership, Plastics Technology and Marketing 28th Anniversary.

[5] Hee, J.L, Yeong, K.Y and Jin,Y.C (2000), Modeling of Industrial High Pressure Autoclave Polyethylene Reactor Including Decomposition Phenomena, Korean J.Chem.Eng., 17 (2) 223-229.

[6] Majid, D. (2009), Comparison of Catalytic Ethylene Polymerization In Slurry and Gas Phase, Ph..D Thesis, University of Twente, The Netherlands.

[7] Frosch, R.A. and N.E. Gallopoulos, (1989) Strategies for Manufacturing. Scientific American, 261 (3) 144-152.

[8] Galli, P. and G. Vecellio,(2001), Technology: driving force behind innovation and growth of polyolefins. Progress in Polymer Science, 26 (8): 1287- 1336.

[9] Galli, P. and G. Vecellio, (2004), Polyolefins: The most promising large-volume materials for the 21 st century. Journal of Polymer Science Part a-Polymer Chemistry, 42 (3) 396-415.

[10] Tannous, K. and J.B.P. Soares,(2002) Gas-phase polymerization of ethylene using supported metallocene catalysts: Study of polymerization conditions.
Macromolecular Chemistry and Physics, 203(13) 1895-1905.

[11] Romano, U. and F. Garbassi, (2000), The environmental issue. A challenge for new generation polyolefins. Pure and Applied Chemistry, 72 (7) 1383-1388.

[12] Knuuttila, H., Lehtinen, A and Nummila-Pakarinen, A (2004), Advanced polyethylene technologies - Controlled material properties. Long-Term Properties of Polyolefins, 169: 13-27.

[13] Montagna, A.A., R.M. Burkhart, and A.H. Dekmezian, (1997), The evolution of single-site catalysis. Chemtech, 27 (12) $26-31$.

[14] Ehrlich, P. and Mortimer, G. A. (1970). Fundamentals of the Free-Radical Polymerization of Ethy lene. Adv. Polym. Sci. 7: 386-448.

[15] Zhang, S.X., Read, N.K., Ray, W.H., (1996), Runaway Phenomenom in Low Density Polyethylene Autoclave Reactor ,AICHE J., 42:2911-2925.

[16] Fogler, H. S. (1999), Elements of Chemical Reaction Engineering. Prentice Hall International Series in the Phy sical and Chemical Engineering Sciences, 3ed.

[17] Costas, P.B, Sundaram, R., John, F. (2001), Physical Properties, Reactor Modeling And Polymerization Kinetics In The Low Density Polyethylene Tubular Reactor Process, Ind.Eng.Chem.Res.41 (5), 1017- 1030.

[18] Buback, M., (1980), The high pressure ethylene polymerization of pure ethylene, Makromol Chem.,18,373.

[19] Luft,G.,Kampf,R.,Seidi,H., (1982),Angew.Makromol.Chem.,108,203.

[20] Yamamoto,K.and Sugimoto.M.(1979), Rate Constants For Long Chain Branch Formation In Free Radical Polymerization of Ethylene,J.Macrom.Sci-chem., 13 (8), 1067 .

[21] Goto, S., Yamamoto, K., Furui, S., and Sugimoto, M.(1981). Computer model for commercial high pressure polyethylene reactor based on elementary reaction rates obtained experimentally. Journal of Applied Polymer Science: AppliedPolymer Symposium, 36, 21-40.

[22] Ogo,Y., (1984), Polymerization at High Pressures, JMS-Rev..Macrom.Chem.Phys., 24 (1),1

[23] Kiparissides, C. (2006). Challenges in Particulate Polymerization Reactor Modeling and Optimization:A Population Balance Perspective.Journal of Process Control 16,205 .

[24] Pladis, P., and Kiparissides, C. (1998). A Comprehensive Model For The Calculation of Molecular Weight-Long-Chain Branching Distribution in Free-Radical Polymerizations.Chemical Engineering Science, 53, 3315-3333.

[25] Ham , J.Y. and Rhee, H.K, (1996) Modeling and Control of an LDPE Autoclave Reactor ,J. Proc.Cont., 6, 241.

[26] Tsutomu, K., and Masatsugu, I(1968) J. Res.nst. Catalysis, Hokkaido Univ., Vol. 16, No.1, pp. 155 - 168.

[27] Agrawal, S. and Han, C.D (1975). AIChE J., 21 (3), 449.

[28] Chen, C. H., Vermey chuk, J. G., Howell, J. A., and Ehrlich, P. (1976). Computer model for tubular high-pressure poly ethylene reactors. AIChE Journal, 22 (3), 463-471. 
[29] Donati, G., L. Marini, G. Marziano, C. Mazzaferri, M. Spempinato, and E.Langianni (1982). Proc. 7th Int. Symp. CHem. Reaction Eng. (Boston), 579.

[30] Lee, K.H. and J.P. Marano (1979). Am. Chem. Sot. Symp. 104, 221.

[31] Luft, G. and H. Seidl (1981). J. Macromol. Sci-Chem., 415 (11) 1-33.

[32] Gupta, S. K., A. Kumar and M.V.G. Krishnamurthy (1985).Simulation of Tubular low density Poly ethy lene.Polym. Engr. Sci., 25 (1) 37-47.

[33] Takahaski, T. and P. Ehrlich (1982). Macromolecules, 15, 714.

[34] Nigam, K.M. and K.D.P. Nigam (1983). J. Appl. Polym. Sci., 281- 887.

[35] Yoon, B.J. and H.K. Rhee (1985). Chem. Eng. Commum.. (34), 253.

[36] Zabisky, R.C.M., Chan,W.M., Gloor, P.E.,and Hamielec ,A.E. (1992), A kinetic model for olefin polymerization in high pressure tubular reactors:a review and update,Polymer, vol.33,No.11,2243-2262.

[37] Thies, J. and K. Schoenemann (1970). 1st Int. Symp. Chem. Reaction Eng,Washington, DC.

[38] Kondratiev, J.N., Ivanchev, S.S., (2005), Possibilities For Optimization of Technological Modes For Ethylene Polymerization in Autoclave and Tubular Reactors,Chem. Eng Journal, 107, 221-226.

[39] Dhib, N; Al-Nidawy, R; (2002), Modeling of Free Radical Polymerization Of Ethylene Using Difunctional Initiators, Chem.Eng. Sci, Vol.57,2735- 2746.

[40] Luft, G., \& Seidl, H. (1985). Application of bifunctional organic peroxides in the polymerisation of ethylene under high pressures. Die Angewandte Makromolekulare Chemie, $129,61-70$

[41] Luft, G., Bitsch, H., \& Seidl, H. (1977). Effectiveness of organic peroxide initiators in the high-pressure polymerisation of ethylene. Journal of Macromolecular Science-Chemistry, 11(6), 1089-1112.

[42] Seidl, H., and Luft, G. (1981). Peroxides as initiators for high-pressure polymerization. Journal of Macromolecular Science-Chemistry, 15(1), 1-33.

[43] Luft, G., Lim, P., Pavlaskis, S., and Seidl, H. (1985). The decomposition of 2,2-bis(t- butylperoxide)butane under high pressure. Journal of Macromolecular Science-Chemistry, 22(9), 1183-1200

[44] Luft, G., and Dorn, M. (1988). Asymmetrical bifunctional organic peroxides as initiators for the high-pressure polymerisation of ethylene. Journal of Macromolecular Science-Chemistry, 25(8), 987-998.

[45] Puts R.D and Sogah D.Y. (1997). Universal multifunctional initiator containing orthogonal reactive sites. Synthesis of macromonomers and comb polymers using consecutive controlled free radical and cationic ring-opening polymerizations. Macromolecules ; 30 (23) 7050-7055.

[46] Hawker ,C.J, Hedrick, J.L, Malmstro, E.E, Trollsas M, Mecerreyes D, and Moineau G, (1998) Dual living free radical and ring opening polymerizations from a double-head ed initiator. Macromolecules; 31 (2) 213-9.

[47] Bernaerts ,K.V, Willet N, Van Camp W, Je'ro^me R, Du Prez FE. (2006) pH-responsive diblock copolymers prepared by the dual initiator strategy. Macromolecules ; 39: 3760-3769.

[48] Matthew, J.S. (2005), Experimental and Modelling Investigation of a Novel Tetrafunctional Initiator In Free Radical Polymerization,Ph.D Thesis University of Waterloo,Canada.

[49] Kiparissides, C., Verros, G., and Mcgregor, J. (1993). Mathematical Modeling, Optimization and Quality Control of High-Pressure Ethylene Polymerization Reactors. Journal of Macromolecular Science-Reviews in Macromolecular Chemistry and phy sics, 33: 437-527.

[50] Brandolin, A.,Capiati, N.J.,Farber, J.N.,Vales, E.M.,(1988), Mathematical model for high pressure tubular reactor for ethylene poly merization,I.\&E.C.Res. 27 (5) 784-790.

[51] Fred, Z.Y., Ali, L., Simant, R.U, Ramdhane, D., (2004), Modeling ,Simulation and Optimal Control of Ethylene Polymerization in Non-Isothermal High Pressure Tubular Reactors, IJCRE,2 (16).

[52] Zhou, W., Marshall, E., Oshinowo, L. (2001) Modeling LDPE Tubular and Autoclave Reactor,I.\&E.C.Res., 40:5533-5542.

[53] Brandolin,A.,Lacunza,M.H.,Ugrin,P.E.,Capiati,N.J.(1996),H igh pressure polymerization of ethylene.An improved mathematical model for industrial tubular reactor,Poly.Reac.Eng.4 (4),193-240.

[54] Mavridis, H., Kiparissides, C. Optimisation of High Pressure Poly ethy lene Tubular Reactor, Pol.Proc.Eng., 3 (3), 263-290, 1985.

[55] Verros, G.D. (2003), Calculation of molecular weight distribution in non-linear free radical copolymerization, Polymer 44 7021-7032.

[56] Bernd, G. (2006), Molecular weight distribution in living polymerization, Progress in Organic Coatings ,55, 189-193.

[57] Odian, G., Principles of Polymerization,pp. 198-349. Wiley, 4th ed., 2004.

[58] Feucht, P., Tilger, B., \& Luft, G. (1985). Prediction of molar mass distribution, number and weight average degree of polymerisation and branching of low density polyethylene. Chemical Engineering Science, 40 (10), 1935-1942.

[59] Lorenzini, P., Pons, M., and Villermaux, J. (1992a). Free-radical polymerization engineering-III. Modelling homogeneous polymerisation of ethylene: Mathematical model and new method for obtaining molecular weight distribution.Chemical Engineering Science, 47(15-16), 3969-3980.

[60] Chan, W. M., Gloor, P. E., \& Hamielec, A. E. (1993). A kinetic model for olefin polymerisation in high-pressure autoclave reactors. AIChE Journal, 39 (1), 111-126.

[61] Shirodkar, P. P. and Tsien, G. O. (1986). A mathematical model for the production of low density polyethylene in a tubular reactor. Chemical Engineering Science, 41(4), 1031-1038.

[62] Xie, T, McAuley, K,B , HSU, J,C and Bacon, D.W, Gas Phase Ethylene Polymerization: Production Processes, 
Polymer Properties, and Reactor Modeling, Ind. Eng. Chem. Res. 1994,33, 449-479.

[63] Ray, W. H. (1986). Modelling of Polymerization Phenomena. Ber. Bunsen- Ges. Phys. Chem. 90,947

[64] Ray, W. H.(1991) . Modelling of Addition Polymerization Processes-Free Radical, Ionic, Group Transfer, and Ziegler-Natta Kinetics. Can. J. Chem. Eng. 69, 626.

[65] Arriola, D.J. (1989), Ph.D. Thesis ,Department of Chemical Engineering,University of Wisconsin,Madison.

[66] Metzler, D.E., Harris, C.M., Johnson, R.A., Siano, D.B., Thomson, J.A., (1973), Spectra of 3- Hydroxypyridines:
Brand Shape Analysis and Evaluation of Tautomeric Equilibria, Biochem., (12) 26,5377-5392.

[67] Hulburt, H.M., Katz,S., (1964) ,Some Problems In Particle Technology: A Statistical Mechanical Formulation,Chem.Eng. Sci., 19: 555-574.

[68] Bernaerts, K.V, Schacht, E.H, Goethals, E.J, Du Prez, F.E. (2003) Synthesis of poly(tetrahydrofuran)-b-polystyrene block copolymers from dual initiators for cationic ring-opening polymerization and atom transfer radical polymerization.J Polym Sci Polym Chem ;41(21):3206-17. 